\title{
Economia como Ciência Teórica e suas Relações com as Ciências Econômicas Históricas e Práticas - Parte $1^{*}$
}

\author{
Carl Menger
}

\begin{abstract}
Resumo: O autor argumenta que a economia teórica não pode ocupar o lugar da história ou da estatística econômica na busca de conhecimento e que a investigação mais abrangente no campo da história ou da estatística também não pode substituir a economia teórica sem deixar um vazio no sistema das ciências econômicas. A compreensão de fenômenos concretos, de qualquer tipo que sejam, deve se distinguir sempre dos fundamentos científicos dessa compreensão, ou seja, da teoria ou da história dos fenômenos correspondentes; e a compreensão teórica dos fenômenos econômicos concretos deve distinguir-se, em particular, da teoria da economia.

Palavras-Chave: Ciências econômicas, Ciências históricas, Ciências práticas, Fenômenos concretos, Fenômenos práticos.
\end{abstract}

\section{Economic as a Theoretical Science and Its Relationship to the Historical and Pratical Economic Sciences - Part 1}

\begin{abstract}
The author argues that theoretical economics can not take the place of history or economic statistics in the pursuit of knowledge and the most comprehensive research in the field of history or statistics can not replace theoretical economics without leaving a vacuum in the system of economics. Understanding concrete phenomena of any kind whatsoever, must always distinguish the scientific basis of this understanding, ie, the theory or history of relevant phenomena; practical and theoretical understanding of economic phenomena should be distinguished, in particular, the economics theory.
\end{abstract}

Keywords: Economics, Historical Sciences, Practical Sciences, Concrete phenomena, Practical phenomena.

Classificação JEL: B13, B41

\footnotetext{
* O presente artigo é a versão integral dos capítulos 1, 2 e 3 do Livro I da obra Untersuchungen über die Methode der Sozialwissenschaften und der politischen Ökonomie insbesondere [Inverstigações sobre o Método das Ciências Sociais com Especial referência à Economia Política], publicado pela primeira vez em alemão no ano de 1883. Nas duas próximas edições de MISES: Revista Interdisciplinar de Filosofia, Direito e Economia serão publicados os demais capítulos do Livro I dessa obra de Carl Menger. A presente tradução foi feita a partir da seguinte versão em inglês: MENGER, Carl. Book One: Economics as a Theoretical Science and Its Relationship to the Historical and Practical Economic Sciences. In: Investigations into the Method of Social Sciences with Special Reference to Economics. Ed. Louis Schneider; Intr. Lawrence H. White; Trad. Francis J. Nock. New York: New York University Press, 1985. p. 33-94. A presente tradução para o português foi cotejada pelo tradutor com a versão em espanhol e pelos editores com o original em alemão, publicados, respectivamente, nas seguintes edições: MENGER, Carl. El método de las ciencias sociales. Trad. Juan Marcos de la Fuente, Madrid Unión Editorial, 2006; MENGER, Carl. Untersuchungen über die Methode der Sozialwissenschaften und der politischen Ökonomie insbesondere. Leipzig: Verlag von Dunker \& Humblot, 1883.

Traduzido do inglês para o português por Davi J. Dias.

* Carl Menger nasceu em 23 de fevereiro de 1840 na cidade de Nowy Sącz, atualmente na Polônia e na época parte do território do Império Austro-Húngaro. Estudou Direito nas universidades de Viena e de Praga, e recebeu o título de Doutor em Direito na Universidade Jaguelônica, em Cracóvia. Trabalhou como jornalista e analista econômico para o Lemberger Zeitung, em Lwów na Ucránia, e para o Wiener Zeitung, em Viena, lecionou Economia Política e Finanças na Faculdade de Direito da Universidade de Viena, foi tutor de Economia Política e de Estatísticas do arquiduque Rudolf von Habsburg (1858-1889) de 1876 a 1878, assumiu a cátedra de Economia Política da Universidade de Viena em 1878 e foi nomeado em 1900 para o conselho imperial de Franz Joseph von Habsburg (1830-1916). É considerado o fundador da Escola Autríaca de Economia, sendo autor de diversos artigos acadêmicos e, dentre outros, do livro Princípios de Economia Política (Abril Cultural, 1983). Faleceu no dia 26 de fevereiro de 1921 em Viena.
} 
I - OS DIFERENTES PONTOS DE VISTA DA INVESTIGAÇÃO NO CAMPO DA CIÊNCIA ECONÔMICA

O mundo dos fenômenos pode ser considerado desde dois pontos de vista essencialmente diferentes. Ou o objeto do nosso interesse científico consiste no conhecimento dos fenômenos concretos, segundo a posição deles no tempo e no espaço e as relações concretas que têm entre si; ou no conhecimento das formas em que esses fenômenos se repetem na variação de suas relações. A primeira orientação visa ao conhecimento do concreto ou, melhor dizendo, do aspecto individual dos fenômenos; a segunda visa ao conhecimento do aspecto geral dos fenômenos. A esses dois modos principais de se orientar ao conhecimento correspondem duas grandes classes de conhecimento científico, que chamaremos, em suma, de conhecimento individual e de conhecimento geral 1 .

São evidentes o interesse do espírito humano pelo conhecimento dos fenômenos concretos (ou seja, pelo individual) e a importância desse conhecimento para a vida prática; $\mathrm{o}$ mesmo se diga sobre a natureza formal dos resultados da aspiração ao conhecimento do individual. A qualidade e o significado do conhecimento geral, porém, são menos evidentes ao entendimento comum, razão pela qual nos é necessário fazer aqui algumas observações, dada a importância do assunto para compreendermos a natureza das ciências teóricas e o que as difere das ciências históricas.

Apesar da grande variedade dos fenômenos concretos, basta uma ligeira observação para constatarmos que nem todo fenômeno singular apresenta uma forma empírica particular diferente da de todos os outros fenô-

\footnotetext{
1 Empregamos aqui a expressão "individual" tão somente em contraposição a "geral", ou seja, para designar a diferença entre os fenômenos concretos [concreten Erscheinungen] e as formas dos fenômenos [Erscheinungsformen]. Evitamos, intencionalmente, usar as expressões "concreto" e "abstrato", por serem ambíguas e não caracterizarem com precisão a diferença assinalada.
}

menos. Ensina-nos a experiência que certos fenômenos se repetem com mais ou menos exatidão e assumem diferentes formas segundo a variação das coisas. A essas formas fenomênicas chamamos tipos. Pode-se dizer isso, também, acerca das relações entre fenômenos concretos: tampouco elas apresentam, sempre, uma singularidade constante em todos os casos concretos. É-nos fácil observar que algumas relações, que chamaremos típicas, se repetem mais ou menos constantemente (por exemplo, na regularidade da sucessão, no desenvolvimento e na coexistência dos fenômenos). Os fenômenos de compra e venda, moeda, oferta e procura, preço, capital e taxa de juros exemplificam formas típicas de fenômenos econômicos. Por outro lado, a queda regular de preço de uma mercadoria, em virtude do aumento da oferta; a elevação do preço das mercadorias, por causa do aumento do dinheiro circulante; a redução da taxa de juros, em consequência de um acúmulo importante de capital, etc., apresentam-se-nos como relações típicas entre os fenômenos econômicos. Dito isso, fica bem clara a diferença entre fenômenos gerais e individuais, conforme os chamamos, e a diferença entre conhecimento geral e conhecimento individual dos fenômenos.

O estudo dos tipos e das relações típicas entre os fenômenos é, sem dúvida, de importância capital para a vida humana, tanto quanto o conhecimento dos próprios fenômenos concretos. Sem o conhecimento das formas empíricas, seríamos incapazes de compreender os inumeráveis fenômenos concretos que nos cercam e de classificá-los mentalmente, já que ele é o pressuposto para um entendimento mais amplo do mundo real. Sem o conhecimento das relações típicas, ficaríamos privados não só de um entendimento mais profundo do mundo real, como se demonstrará adiante, mas também - e isso facilmente se compreende - de todo e qualquer conhecimento além do que é imediatamente observável, ou seja, de toda e qualquer previsão e controle sobre as coisas. Ora, a previsão_humana e, de modo indireto, tudo o que fazemos para moldar as coisas ao nosso arbítrio estão 
condicionados por aquele conhecimento que denominamos geral.

As afirmações feitas aqui valem para todos os campos do mundo dos fenômenos e, portanto, também para a economia humana em geral, e, em particular, para a sua forma social, ou simplesmente economia (Volkswirtschaft) ${ }^{2}$. Podemos também considerar os fenômenos econômicos a partir dos dois pontos de vista referidos; e também podemos distinguir, por um lado, os fenômenos individuais (concretos) e as suas relações individuais (concretas) no tempo e no espaço, e, por outro lado, os tipos (formas empíricas) e as suas relações típicas (as leis, no sentido mais amplo do termo). Do mesmo modo, no campo econômico, temos os fenômenos individuais e os fenômenos gerais e, por conseguinte, as ciências que tratam do aspecto individual dos fenômenos e as ciências que tratam do seu aspecto geral. Às primeiras pertencem a história econômica e a estatística econômica; às segundas, a economia teórica. A história econômica e a estatística econômica têm por fim investigar os fenômenos econômicos individuais ${ }^{3}$, sob

${ }^{2}$ Ver: "Apêndice I: A Natureza da Economia Nacional". [N. do T.: MENGER, Carl. Appendix I: The Nature of National Economy. In: Investigations into the Method of Social Sciences with Special Reference to Economics. Ed. Louis Schneider; Intr. Lawrence H. White; Trad. Francis J. Nock. New York: New York University Press, 1985. p. 193-96].

${ }^{3}$ Não se deve de modo algum confundir o "individual" com o "singular", quer dizer, não se deve confundir os fenômenos individuais com os fenômenos singulares. Com efeito, o oposto de "individual" é "geral", ao passo que o oposto de um "fenômeno singular" é um "fenômeno coletivo". Determinada nação, determinado Estado, uma economia concreta, uma cooperativa, um município etc. são exemplos de fenômenos individuais, mas não são absolutamente fenômenos singulares (aliás, são fenômenos coletivos). $O$ fato de as ciências históricas da economia descreverem os fenômenos individuais a partir do ponto de vista individual não exclui absolutamente que cheguem ao nosso conhecimento desde o ponto de vista coletivo. Contudo, a contraposição entre a investigação e a descrição do aspecto individual e geral dos fenômenos humanos será sempre aquilo que distingue as ciências sociais históricas das teóricas. diferentes pontos de vista. A economia teórica visa a investigar as formas empíricas e as leis (ou seja, a natureza e as conexões gerais) dos fenômenos econômicos ${ }^{4}$.

O referido contraste não raro se caracteriza, ainda que num sentido algo diferente, pela separação das ciências em históricas e teóricas. A história e a estatística da economia são ciências históricas no sentido exposto anteriormente, ao passo que a economia é uma ciência teórica ${ }^{5}$.

Além dos dois grandes grupos de ciências mencionados, devemos assinalar aqui

${ }^{4}$ Cabe à economia teórica investigar a natureza geral e a conexão geral dos fenômenos econômicos; mas não é sua função analisar os conceitos econômicos e tirar disso as conclusões lógicas. Os fenômenos, ou certos aspectos deles - e não a sua descrição linguística (os conceitos) - constituem o objeto da investigação teórica no campo da economia. A análise dos conceitos pode ter, em determinados casos, alguma importância para a apresentação dos conhecimentos teóricos da economia, mas o objetivo da investigação no campo da economia teórica só pode ser o de determinar a natureza geral e a conexão geral dos fenômenos econômicos. Alguns representantes da Escola Histórica revelam uma compreensão escassa dos objetivos da investigação teórica quando, em investigações sobre a essência dos bens, sobre a essência da economia, do valor, do preço e de semelhantes objetos, enxergam apenas análises conceituais, e, na busca de uma ciência dos fenômenos econômicos, somente " $O$ estabelecimento de um sistema de conceitos e juízos" (ver, em particular: ROSCHER, Wilhelm. Leben, Werk und Zeitalter des Thukydides: mit einer Einleitung zur Aesthetik der historischen Kunst überhaupt. Göttingen: Vandenhoeck, 1842. p. 27). Muitos economistas franceses incidem em tal erro quando, com uma visão errônea dos conceitos de "teoria" e "sistema", não entendem por estes termos nada além de teoremas e construções doutrinais obtidos dedutivamente de axiomas a priori (Ver, particularmente: SAY, Jean-Baptiste. Cours complet d'économie politique pratique. Paris: Guillaumin, $3^{\mathrm{a}}$ ed., 1852. p. 14ss.). Também, Joseph Garnier (1813-1881) afirma: "Por uma doutrina equivocada é que se emprega a palavra 'Système' em economia política" (GARNIER, Joseph. Traité d'economie politique. Paris: Garnier Frères / Guillaumin et Cie, 1868. p. 648).

${ }^{5}$ Ver: "Apêndice II: O Conceito de Economia Teórica e a Natureza de suas Leis". [N. do T.: MENGER, Carl. Appendix II: The Concepts of Theoretical Economics and the Nature of Its Laws. In: Investigations into the Method of Social Sciences with Special Reference to Economics. p. 197-202]. 
um terceiro, cuja natureza difere essencialmente da dos dois primeiros: referimo-nos às chamadas ciências práticas, ou artes.

As ciências dessa espécie nada nos dizem, do ponto de vista histórico ou teórico, sobre a natureza dos fenômenos; em geral, não nos ensinam nada sobre o que é. Tratam de determinar os princípios básicos que nos podem guiar para melhor alcançarmos certos resultados, tendo em vista as diversas circunstâncias. Essas ciências nos ensinam - considerando sempre as condições concretas - o que deveria ser para que determinados objetivos sejam alcançados. A esta classe de ciências práticas, no campo da economia política, pertencem a política econômica e a ciência das finanças.

Para os nossos objetivos, portanto, podemos distinguir três grupos de ciências no âmbito da economia. Em primeiro lugar, as ciências históricas (a história ${ }^{6}$ ) e a

${ }^{6}$ Karl Gustav Adolf Knies (1821-1898) especifica a função da história econômica da seguinte maneira:

Ela não deve apenas compreender e descrever o desenvolvimento histórico da teoria econômica, os propósitos e a práxis dos poderes gerais do Estado, para satisfazer às suas necessidades materiais e para atender aos interesses econômicos da nação [Volksinteressen], mas também as condições e os desenvolvimentos econômicos na vida concreta das diversas nações e tempos (KNIES, Karl Gustav Adolf. Die politische Ökonomie vom Standpunkt der geschichtlichen Methode. Braunschweig: C. S. Schwetschke und sohn, 1853. p. 3 e segs.).

Entendemos que a função da história econômica é tripla: 1) investigar as fontes da história econômica; 2) fazer a crítica interna e externa dessas fontes; e 3) descrever o desenvolvimento daqueles fenômenos coletivos que chamamos de "economia", com base no material histórico obtido. Quanto mais abrangente for o estudo dessas fontes, mais precisa e metódica será a crítica delas e a arte da descrição, e tanto mais o historiador será capaz de nos oferecer um retrato uno, que faça justiça às condições reais da história econômica de nações particulares, de determinados grupos de nações e até da humanidade. Por outro lado, parece-nos pouco científico o procedimento daqueles que se limitam a compilar a história econômica das nações com meras coleções de dados, sem recorrer às fontes originais e sem submetê-las ao menor exame crítico. E nos parece particularmente anticientífica a atitude daqueles que apresentam um estatística ${ }^{7}$ econômica, que têm por finalidade investigar e descrever a natureza individual e a conexão individual dos fenômenos econô-

conjunto de material histórico organizado mais ou menos superficialmente, sem inserir esse material num quadro uno, coerente, dos desenvolvimentos econômicos, e qualificam de "história" essas coleções de fatos mal submetidos à crítica.

7 A estatística, enquanto ciência histórica, apresenta as mesmas funções da história, se bem que não em relação ao desenvolvimento, mas sim ao estado [situação] das sociedades. As compilações feitas sem critério crítico, ou as enumerações puramente externas de material estatístico, sem uma unidade superior, não pertencem ao domínio da descrição científica. As definições da estatística histórica como "história estática", como "média do desenvolvimento histórico" ou como "descrição da sociedade em determinado momento" e outras semelhantes dão ensejo a uma grande variedade de falsas concepções sobre a verdadeira natureza dessa ciência. A estatística histórica não tem, por objetivo, apresentar a configuração externa da sociedade em determinado momento, configuração que pode variar segundo o período escolhido, e que, ademais, não poderia deixar de ser uma representação bastante incompleta da vida do povo, considerada em sua totalidade. De fato, a estatística histórica tem a função de oferecer a descrição de todos os fatores da vida social (mesmo daqueles fatores latentes em determinado momento), dos quais resulta o movimento da sociedade, ao passo que a história deve retratar esse movimento em si. Devem-se distinguir da estatística, enquanto ciência histórica, os dados estatísticos obtidos das observações em massa, os quais se apresentam - em relação à estatística histórica e à estatística teórica como simples material científico. Os meros dados estatísticos não podem pretender ser a estatística, assim como as fontes históricas descobertas ou os fatos históricos criticamente comprovados não constituem a "história" em si. Também, está claro, deve-se distinguir o método para a elaboração das estatísticas, da descrição científica dos resultados estatísticos. A "estatística como ciência" não pode jamais ser apenas um método. O que em geral se chama de "teoria da estatística" é, segundo sua natureza, sobretudo a metodologia (a chamada teoria do conhecimento!) dessa ciência. Para sermos mais rigorosos, somente os resultados de uma autêntica consideração teórica do material estatístico, as leis da coexistência e da sucessão dos fenômenos sociais, deveriam ser designados como conhecimento teórico-estatístico, ao passo que o conjunto de ambos os conhecimentos constitui a estatística teórica. As "leis dos grandes números" constituem a parte mais importante da estatística teórica, mas de forma alguma o seu conteúdo exclusivo. 
micos. Em segundo lugar, a economia teórica, que visa a investigar e descrever a natureza geral e a conexão geral (as leis) desses fenômenos. Por fim, em terceiro lugar, temos as ciências práticas $^{8}$ da economia, que têm, por finalidade, investigar e descrever os fundamentos em que se pode basear a ação adequada ao fim, no campo da economia, levando em conta as várias circunstâncias (a política econômica e a ciência das finanças).

Por Economia Política, enfim, entendemos o conjunto das ciências teórico-práticas ${ }^{9}$

\footnotetext{
${ }^{8}$ Ver: "Apêndice III: A Relação das Ciências Práticas da Economia com a Práxis Econômica e a Economia Teórica". [N. do T.: MENGER, Carl. Appendix III: The Relationship of the Practical Sciences of National Economy to Economic Practice and to Theoretical Economics. In: Investigations into the Method of Social Sciences with Special Reference to Economics. p. 203-05].
}

9 O poeta, dramaturgo e economista Antoine de Montchrêtien (1575-1621), senhor de Vateville, que, em 1615, publicou em Rouen, pela casa editorial Jean Osmont, seu Traicté de l'économie politique [Tratado de Economia Política], foi, ao que parece, o primeiro a empregar a expressão "économie politique" [economia política]. Esta expressão, que alcançaria larga circulação, aparece, no entanto, apenas no título da obra, e não nos créditos, em que o termo é designado como Traicté économique du profit [Tratado de Economia do Lucro], e em nenhuma outra parte do texto. Parece, portanto, ter sido resultado de uma inspiração momentânea do autor, e talvez tenha sido tomada de empréstimo a um escrito contemporâneo, quando sua obra já estava impressa. Esta, dividida em três livros, sobre a indústria, o comércio e a navegação, é, sobretudo, uma teoria da práxis econômica (ver: GARNIER, Joseph. Mémoire sur Antoine de Montchrêtien. Paris: Guillaumin et. cie, 1868). A expressão "Politische Oekonomie" [economia política] já fora referida na obra pseudoaristotélica Oikovo $\mu \iota \kappa \tilde{\omega} v$ [A Economia], embora apenas no sentido de economia de uma cidade. No latim medieval, a palavra "politia", ou, mais frequentemente, "politica", é usada no sentido da arte de governar (nos glossários mais antigos, estes termos se traduzem como "ordenamento estatal, governo de um Estado, arte de governar o Estado, uma arte de governar os Estados"). Oeconomia tem geralmente, no latim medieval, o sentido de praedium, villa rustica; Oeconomus, o sentido de advogado, defensor, advocatus etc. Não encontrei a combinação das duas expressões em nenhum lugar, nem nos escritores antigos, nem entre os Padres da Igreja (ver: DU CANGE, Charles Du Fresne. Glossarium mediae at infimae latinitatis. Paris: (a economia teórica, a política econômica e a ciência das finanças), que hoje são normalmente agrupadas sob a designação citada ${ }^{10}$.

\section{II - OS ERROS DECORRENTES DO DESCONHECIMENTO DA NATUREZA FORMAL DA ECONOMIA TEÓRICA}

No Livro II ${ }^{11}$, analisaremos detidamente a natureza e o significado do chamado ponto de vista histórico na Economia Política, assinalando os erros que derivam, para a nossa ciência, de uma concepção errônea de tal perspectiva, isto é, daquilo que se pode chamar de ponto de vista anti-histórico na Economia Política. Antes de prosseguirmos à solução deste problema, porém, devemos nos referir aos erros que derivam do desconhecimento da natureza formal da Economia Política e de seu lugar no âmbito das ciências. E isso porque não apenas estes erros são cometidos de modo particular entre os economistas alemães, mas também, como demonstraremos a seguir, porque se fundamentam na tentativa - em si legítima, mas até agora pouco clara e mal orientada de impor o ponto de vista histórico à nossa ciência. Aqui trataremos, primeiro, da confusão entre a investigação histórica e a investigação teórica no campo da Economia, e, a seguir, da confusão entre ciências econômicas teóricas e ciências econômicas práticas.

Firmin Didot, 1845. Vol. V, p. 333ss. e Vol. IV, p. 696. Ver, também: DIEFENBACH, Laur. Glossarium Latinogermanicum. Frankfurt: Baer, 1857. p. 445). Os escritos publicados antes de Montchrêtien tratam, sempre em sintonia com a terminologia aristotélica, de política ou de economia, mas nunca de economia política.

10 Ver: "Apêndice IV: Terminologia e Classificação das Ciências Econômicas". [N. do T.: MENGER, Carl. Appendix IV: The Terminology and the Classification. In: Investigations into the Method of Social Sciences with Special Reference to Economics. p. 206-13].

${ }^{11}$ Ver: "Livro II: O ponto de Vista Histórico na Pesquisa Econômica". [N. do T.: MENGER, Carl. Book Two: The Historical Point of View in Economic Research. In: Investigations into the Method of Social Sciences with Special Reference to Economics. p. 95-125]. 
Ressaltamos acima que se podem investigar os fenômenos a partir de um duplo ponto de vista: o individual (histórico, no sentido mais amplo da palavra) e o geral (teórico). O objetivo da primeira orientação é conhecer os fenômenos concretos em sua natureza individual e em suas relações individuais. O fim da segunda orientação é conhecer as formas dos fenômenos (tipos) e as relações típicas (as leis dos fenômenos). São os atos concretos, os destinos, as instituições de determinadas nações ou Estados, são os desenvolvimentos e as condições culturais concretas que constituem o objeto de investigação da história e da estatística - ao passo que as ciências sociais teóricas visam a nos mostrar as formas em que se manifestam os fenômenos sociais e as leis de sua sucessão, de sua coexistência etc.

A contraposição entre ciências históricas e ciências teóricas torna-se ainda mais evidente se nos referimos a uma deteterminada ordem de fenômenos. Se, para esse propósito, selecionarmos os fenômenos econômicos, a função da investigação teórica será determinar as formas fenomênicas e as leis dos fenômenos econômicos, os seus tipos e as suas relações típicas. Contribuiremos para o desenvolvimento da economia teórica se procurarmos determinar que formas empíricas são recorrentes na sucessão dos fenômenos econômicos: por exemplo, a natureza geral da troca, do preço, da renda da terra, da oferta, da procura e das relações típicas entre estes fenômenos; por exemplo, o efeito do aumento e da diminuição da oferta e da procura sobre os preços, o efeito do aumento demográfico sobre a renda da terra etc. Por outro lado, as ciências históricas da economia nos apresentam a natureza e o desenvolvimento de fenômenos econômicos individuais, como, por exemplo, a situação e o progresso da economia de um determinado país ou grupo de países, a situação e o progresso de uma determinada instituição econômica, a marcha dos preços ou da renda da terra em uma determinada região etc.

Logo, as ciências teóricas e as ciências históricas da economia revelam uma diferença fundamental entre si, e apenas um completo desconhecimento de sua verdadeira natureza pode nos levar a confundi-las ou a pensar que podem substituir-se reciprocamente.

Ora, é evidente que, assim como a economia teórica não pode jamais ocupar o lugar da história ou da estatística econômicas em nossa busca de conhecimento, tampouco a investigação mais abrangente no campo da história ou da estatística pode substituir a economia teórica sem deixar um vazio no sistema das ciências econômicas ${ }^{12}$.

Se, mesmo assim, alguns dos que escrevem sobre temas econômicos pensam tratar de economia, quando, na verdade, tratam de temas históricos no campo da Economia, impõe-se, de fato, a necessidade de investigar a explicação de tamanho equívoco. A análise seguinte trata, pois, de responder a esta pergunta, que, no que diz respeito à Escola Histórica de Economia alemã, tem grande importância prática.

O objetivo da investigação científica não é apenas o conhecimento, mas também a compreensão dos fenômenos. Conhecemos um fenômeno quando sua representação intelectual alcança nossa mente. Compreendemo-lo quan-

12 Sobre a confusão que prevalece em relação a este problema elementar de metodologia econômica, ver também: ROSCHER, Wilhelm Georg Friedrich. System der Volkswirthschaft - Volume I: Die Grundlagen der National Ökonomie. Stuttgart: Colta, 1854. §26. Nesta obra Wilhelm Georg Friedrich Roscher (18171894) indica como tarefa da teoria a simples descrição, primeiro da natureza e das necessidades econômicas da nação, segundo das leis e das instituições que visam à satisfação dessas necessidades, e, por fim, dos resultados mais ou menos favoráveis alcançados por essas leis e instituições, sendo os resultados desta investigação referidos como "por assim dizer, a anatomia e a fisiologia da economia" (!). Ademais, já entre outros membros da Escola Histórica observa-se uma reação contra esta confusão, mais evidente na prática do que na teoria. Atestam-no os escritos mais recentes como o já citado Karl Gustav Adolf Knies, ou Gustav von Schmoller (1838-1917), Adolf Held (1844-1880) e, por último, Hans von Scheel (1839-1901). Nesse particular, ver o prefácio escrito por Hans von Scheel em: INGRAM, John K. Die nothwendige Reform der Volkswirthschaftslehre. Iena: Gustav Fisher, 1879. p. VI. Tal erro de Roscher assemelha-se àquele que, no campo da Ciência do Direito, identifica a História do Direito com a Jurisprudência Histórica. 
do apreendemos a razão de sua existência e de sua configuração específica (ou seja, a razão de seu ser e de seu ser assim).

Podemos compreender os fenômenos sociais de duas maneiras.

Compreendemos um fenômeno concreto de um modo especificamente histórico (ou seja, por meio de sua história) quando investigamos seu processo individual de formação, isto é, quando apreendemos as relações concretas em que se desenvolveu e se tornou o que é, de fato, com as suas características particulares.

Sabe-se o quanto a compreensão de uma série de importantes fenômenos sociais progrediu graças à investigação histórica, com um método especificamente histórico, $\mathrm{e}$ o muito que a ciência alemã, de maneira louvável, contribuiu nesse sentido. Apenas chamo a atenção para o direito e a linguagem. $\mathrm{O}$ direito de um determinado país e a língua de um determinado povo são fenômenos concretos que podemos compreender melhor por meio de seu processo de formação, ou seja, investigando o seu desenvolvimento progressivo, as influências recebidas etc., do que por meio da simples investigação de seu estado presente, por mais profundo e minucioso que seja esse exame. "O material jurídico" - diz Friedrich Carl von Savigny (17791861) - "apresenta-nos o passado das nações" [...], "surge da natureza profunda e da história das nações". "A história" - continua o autor "não é uma mera coleção de fatos, senão o único (!) caminho para o verdadeiro conhecimento de nossa situação presente"13. E em outro lugar, afirma Savigny: "A visão histórica do Direito" [...] "atribui a maior importância ao conhecimento da conexão vital que une o presente ao passado, sem a qual podemos perceber apenas as formas externas do direito atual, sem compreender a sua natureza profunda"14.

13 SAVIGNY, Friedrich Carl von. Über den Zweck dieser Zeitschrift. Zeitschrift für geschichtliche Rechtswissenschaft, Bd. I 1815. Vol. I, p. 6.

${ }^{14}$ Idem. System des heutigen Römischen Rechtes. Berlin: Veit, 1840. Vol. I, p. XV.
Descessário dizer que esta orientação de pesquisa, em si plenamente legítima, pode também aplicar-se, por analogia, aos fenômenos econômicos. Para compreender determinadas instituições, atividades e resultados econômicos, ou o estado da legislação econômica de um determinado país e coisas semelhantes, pode ser útil (como no campo do Direito) o estudo de seu desenvolvimento, isto é, a partir de uma perspectiva especificamente histórica. A compreensão especificamente histórica dos fenômenos concretos também cabe perfeitamente ao campo da Economia.

Todavia, a investigação científica não se esgota, de maneira nenhuma, na compreensão histórica de fenômenos sociais concretos ${ }^{15}$. Ora, a compreensão teórica dos fenôme-

${ }^{15}$ Aqueles que veem um paralelismo entre a orientação histórica no campo da economia teórica e no campo do direito, e pensam que se pode simplesmente transportar o ponto de vista metodológico da Escola Histórica do Direito para a nossa ciência, fecham os olhos para uma circunstância muito importante. A Escola Histórica do Direito não reconhece, juntamente com o estudo do Direito em suas formas concretas e em sua evolução histórica, uma ciência teórica do Direito em sentido estrito. Para a Escola Histórica do Direito, a Ciência do Direito é certamente uma ciência histórica e seu objetivo é a compreensão histórica do Direito, com a qual apenas a dogmática segue defendendo a sua legitimidade. No campo da Economia, por outro lado, os mais avançados representantes da orientação histórica admitem uma ciência da natureza geral e leis dos fenômenos econômicos, uma teoria destes últimos. Por conseguinte, a orientação histórica não deve se basear na negação do caráter teórico da ciência econômica, afirmando-se como via exclusiva para a compreensão dos fenômenos econômicos. Ora, só podemos buscar racionalmente a peculiaridade de tais fenômenos se mantivermos o ponto de vista histórico na teoria da economia. O que a Escola Histórica do Direito deseja, e o que os partidários do método histórico em Economia hão de desejar - ao menos enquanto se mantiver o caráter desta última como ciência teórica - se resume simplesmente à diferença entre história e teoria, ou melhor, entre a história, por um lado, e a teoria ilustrada por estudos históricos, de outro lado. Ambas as escolas, apesar de seu lema comum, mantêm um contraste metodológico radical. E, portanto, a transposição mecânica dos postulados e dos pontos de vista da histórica ciência das leis e do direito para a nossa ciência é um processo com o qual ninguém versado em assuntos metodológicos pode, absolutamente, concordar. 
nos sociais, com idêntico valor e significado, se contrapõe à compreensão histórica. Compreendemos um fenômeno concreto de uma maneira teórica (de acordo com as ciências teóricas correspondentes), ao reconhecer que se trata de um caso particular de certa regularidade, de uma lei que regula a sucessão ou a coexistência dos fenômenos. Em outras palavras, descobrimos as razões da existência e da peculiaridade da natureza de um fenômeno concreto ao vermos nele, sobretudo, um caso das leis que regulam os fenômenos em geral. Assim, para falarmos de casos concretos, compreendemos, de maneira teórica, o aumento do valor da renda da terra, a diminuição dos juros do capital etc., quando os fenômenos correspondentes apresentam-se (de acordo com os nossos conhecimentos teóricos) simplesmente como exemplificações particulares das leis da renda da terra, dos juros do capital etc. Tanto a história, como a teoria dos fenômenos sociais em geral, e dos econômicos em particular, nos proporcionam uma compreensão certa dos fenômenos sociais e econômicos. Contudo, ambos os conhecimentos diferem essencialmente um do outro, assim como a teoria difere da história.

Nossos economistas da Escola Histórica nem sempre distinguem claramente estes dois modos de conhecer os fenômenos econômicos, tão diferentes em sua natureza e seus fundamentos. Daí que se formasse a opinião de que, no que diz respeito à compreensão dos fatos econômicos, era possível substituir a teoria pela história e, vice-versa, a história pela teoria da economia. Acredito ser esse o primeiro motivo daquela confusão da história e da teoria da economia, de que a referida escola de economistas nos proporciona um precioso exemplo, ao identificar a aspiração à compreensão histórica dos fenômenos econômicos com a atividade de orientação histórica na economia teórica.

Some-se a isso outra circunstância que contribuiu ainda mais para a incerteza, assinalada acima, acerca da natureza formal da economia teórica e da posição que ocupa entre as ciências econômicas.
A compreensão de fatos concretos, instituições, relações etc., em suma, a compreensão de fenômenos concretos, de qualquer tipo que sejam, deve se distinguir sempre, rigorosamente, dos fundamentos científicos dessa compreensão, isto é, da teoria ou da história dos fenômenos correspondentes; e a compreensão teórica dos fenômenos econômicos concretos deve distinguir-se, em particular, da teoria da economia. Naturalmente, não se deve confundir a atividade científica orientada a estabelecer e expor a teoria econômica, com a atividade que explica os fenômenos econômicos concretos de acordo com esta teoria. Não basta possuir um conhecimento teórico de fenômenos concretos, por mais minucioso e abrangente que seja - baseado inclusive nas teorias dominantes! - para ser, de fato, um teórico da economia. Somente quem se propõe precisamente a construir e descrever a teoria pode se considerar como tal. A compreensão de fenômenos econômicos concretos à luz da teoria, a aplicação da economia teórica como instrumento de conhecimento, o emprego da teoria econômica no estudo da história da economia são tarefas do historiador, para quem as ciências sociais teóricas são, a este respeito, ciências auxiliares.

Se resumirmos o que vimos podemos dizer ser fácil responder à pergunta sobre a verdadeira natureza dos erros que os economistas alemães da Escola Histórica cometeram ao conceber a economia teórica como ciência histórica. Não distinguem o conhecimento propriamente histórico do conhecimento teórico, mas os confudem. Isto é, confundem a atividade orientada para a compreensão dos fenômenos concretos por meio da história, ou melhor, por meio da teoria da economia, com a investigação própria destas ciências, em particular da economia teórica. Ao pretenderem explicar os fatos concretos e os desenvolvimentos da vida econômica recorrendo à história e à teoria econômica, acreditam estar contribuindo para a construção e a exposição da economia, aprofundando com isso este tipo de conhecimento.

Incidem em erro análogo, sobre a natureza da economia teórica e o lugar que ocupa 
entre as ciências sociais, aqueles que confundem a economia teórica com a política econômi$c a$, ou seja, confundem a ciência da natureza geral e a conexão dos fenômenos econômicos com a ciência dos critérios que devem orientar a direção prática e o progresso da Economia. O erro não é menor do que se se confundisse a Química com a tecnologia química, a Anatomia e a Fisiologia com a terapêutica e a cirurgia etc. Isso já foi tão bem elucidado pela teoria do conhecimento, que consideramos desnecessário insistir no assunto. Se, apesar de tudo, este erro foi cometido não apenas nos primórdios de nossa ciência, mas continua, ainda que esporadicamente, sendo cometido ainda hoje na literatura econômica ${ }^{16}$, e, apesar de todas as concessões de princípio, segue influenciando em grande medida a metodologia e a sistemática de nossa ciência, impõe-se a necessidade de buscar a razão do desenvolvimento histórico peculiar do conhecimento teórico em geral e do conhecimento econômico em particular.

O conhecimento teórico desenvolveu-se em todas as partes apenas gradualmente, a partir do conhecimento prático e com a crescente necessidade de uma fundamentação científica mais profunda para a práxis. O conhecimento teórico no campo da economia também seguiu este caminho; também tinha, no início, o caráter de máximas práticas derivadas de motivações ocasionais, e, ainda hoje, conserva, naturalmente, rastros dessa procedência e de sua subordinação original à política econômica. Todavia, em todas as questões de metodologia e de sistemática de nossa ciência, surge com toda a clareza, no estado atual do conhecimento econômico, a importância de distinguir bem o conhecimento teórico do prático, e as nefastas consequências que resultam da confusão das duas ciências mencionadas.

A exposição conjunta de conhecimentos teóricos e práticos implica necessariamente que se dê aos conhecimentos práticos o tra-

\footnotetext{
16 Ver recentemente, por exemplo: PRICE, Bonamy Practical Political Economy. London, C. K. Paul \& co., 1878. p. 1ss.
}

tamento sistemático dos conhecimentos teóricos, e vice-versa. É claro que este processo impede que as ciências teóricas sejam tratadas de um modo rigorosamente sistemático, conforme exige a sua natureza; e, no que tange às ciências práticas, atrapalham continuamente a sua exposição.

Acrescente-se a isso o fato de que um tratamento conjunto destes dois grupos de conhecimentos científicos quase impossibilita uma exposição completa. Pelo menos sob a forma em que tal tratamento se afirmou recentemente em nossa ciência, a exposição oferece certamente, de maneira mais ou menos completa, a teoria da economia, mas trata de política econômica apenas de passagem e de modo bastante fragmentário. Tais explicações de economia política não tornam inúteis, de modo algum, os escritos consagrados especificamente à política econômica; e, salvo quando evidente a necessidade de longas exposições de política econômica, não percebemos que benefício a combinação de conhecimentos teóricos e práticos pode trazer propriamente às exposições de economia política.

Essa combinação dos pontos de vista teórico e prático exerceu uma influência particularmente nefasta sobre a investigação teórica no âmbito de nossa ciência. Com efeito, se a economia teórica e a economia prática não se mantiverem rigorosamente separadas, que valor terão as investigações sobre $o$ método da economia política, isto é, sobre $o$ método de duas ciências (uma teórica e outra prática) de natureza tão distinta, ou seja, o método de uma ciência que engloba a teoria econômica, a política econômica e a ciência das finanças?

Não se pode negar que os economistas alemães souberam evitar, melhor do que os demais, semelhante erro, evitando com isso, ao menos em parte, os efeitos na metodologia e na sistemática de nossa ciência. Para isso, contribuiu bastante o fato de os cameralistas alemães terem sentido a viva necessidade de oferecer descrições completas da administração econômica pública.

Por outro lado, o outro erro mencionado, a saber, a confusão de ambos os pontos 
de vista, o teórico e o prático, na investigação econômica, levou - precisamente na literatura alemã - às consequências mais desconcertantes. Tal erro, derivado do desejo, plenamente legítimo, de ampliar e aprofundar a compreensão histórica dos fenômenos econômicos concretos, influiu de maneira assaz negativa, tanto na metodologia, como na sistemática de nossa ciência; na sistemática, porque, a fim de afirmar o "método histórico" em nossa ciência, se considera conveniente interromper a exposição teórica com inumeráveis referências históricas; na metodologia, porque se transportam erroneamente pontos de vista e postulados da investigação histórica para a metodologia da economia teórica.

Mas também no campo próprio da investigação teórica este erro comprometeu seriamente o progresso de nossa ciência. Pode-se culpar a maioria dos representantes desta escola - e não uma minoria insignificante - de se terem ocupado da história econômica, e de se terem aprofundado na compreensão dela, ao mesmo tempo em que, explícita ou ao menos implicitamente, partiam do pressuposto de que estavam expondo e desenvolvendo a teoria econômica a partir do ponto de vista histórico. A aspiração legítima destes estudiosos de superar o anti-historicismo na economia teórica levou-os a sacrificar o caráter teórico desta ciência e a substituir a investigação teórica em geral, e, em particular, a que se fundamenta no ponto de vista histórico, pela mera investigação histórica, ou seja, pela historiografia.

Não é preciso ressaltar que, principalmente em decorrência deste equívoco, a investigação no campo da economia teórica na Alemanha tem sido improdutiva. Nas últimas décadas, por obra de alguns diligentes economistas alemães, teve início e se desenvolveu o conhecimento histórico de alguns setores da vida econômica, ao passo que a teoria econômica - e não somente a que rejeita o ponto de vista histórico, mas a teoria econômica em geral - ficou claramente para trás.

Não pretendemos, de maneira nenhuma, depreciar o mérito dos economistas da
Escola Histórica por terem destacado, como princípio, o ponto de vista histórico na Economia Política em geral e na economia teórica em particular, embora a forma em que esse princípio se expressou até agora careça, como veremos a seguir, tanto de clareza, como de lógica. Ninguém que seja de fato imparcial, por maior importância que atribua ao ponto de vista histórico em nossa ciência, poderá negar que mesmo o mais completo desconhecimento desse ponto de vista não pode, nem de longe, comparar-se com o erro que confunde a economia teórica com a história da economia. Assim, o erro que grande parte dos economistas alemães cometeu, ao ignorar a natureza formal da economia teórica e o lugar que ocupa entre as ciências, é muito mais grave do que o cometido pelos economistas de qualquer outra orientação anti-histórica, porque se trata precisamente do erro fundamental em que toda escola pode incidir: passar por cima da própria ciência que ela supõe estar desenvolvendo.

Se a economia teórica fosse hoje uma ciência já bastante desenvolvida, ou ao menos uma ciência bem definida em suas linhas essenciais, poder-se-ia contornar semelhante equívoco, que pelo menos beneficia os estudos históricos no campo da economia. Mas como fazê-lo com uma escola que se tornou vítima desse mesmo equívoco, com uma ciência cujos fundamentos ainda não foram estabelecidos de maneira definitiva e em que quase tudo permanece em aberto?

Aos supramencionados estudiosos, comumente excelentes historiadores, mas teóricos fracos aplica-se perfeitamente uma observação casual, feita por Adam Smith (1723-1790), o grande fundador de nossa ciência, acerca de determinados sistemas científicos:

Sistemas cujas origens se deveram, em toda a parte, às elucubrações dos que conheciam a primeira arte, mas ignoravam a outra, e que, portanto, explicavam para si mesmos os fenômenos daquela (arte) que lhes era 
estranha mediante aqueles (fenômenos) da arte com que estavam familiarizados ${ }^{17}$.

\section{III - A NATUREZA PARTICULAR DO CONHECIMENTO TEÓRICO NO CAMPO \\ DA ECONOMIA NÃO INVALIDA SEU CARÁTER DE CIÊNCIA TEÓRICA}

Os tipos e as relações típicas (as leis) do mundo fenomênico não apresentam, todos, o mesmo rigor. Uma simples olhadela nas ciências teóricas mostra-nos que a regularidade na coexistência e na sucessão dos fenômenos, por vezes, não admite exceções; ou melhor, é tal que exclui até mesmo a possibilidade da exceção; outras vezes, apresenta exceções ou, pelo menos, a possibilidade de existirem. Os primeiros fenômenos denominam-se leis naturais; os últimos, leis empíricas.

Ora, a opinião mais disseminada entre os metodologistas é a de que, em alguns setores do mundo fenomênico, sobretudo no dos fenômenos naturais, pode haver, de fato, tipos e relações típicas rigorosas, ao passo que, em outros campos, especialmente no âmbito dos fenômenos sociais, esse rigor é menor. Em outras palavras, só ao primeiro caso se aplicam "leis naturais", enquanto que, no segundo, é possível observar apenas "leis empíricas". Demonstraremos, a seguir, que esta opinião, muito difundida na teoria geral da ciência, é errônea. Por ora, limitamo-nos a dizer que tal erro consiste em tomar, como consequência da natureza distinta dos fenômenos, aquilo que, na verdade, à luz de um exame mais atento, se apresenta como resultado de diferentes orientações na investigação teórica, segundo veremos mais adiante. O que gostaríamos, no entanto,

\footnotetext{
${ }^{17} \mathrm{SMITH}$, Adam. History of Astronomy. In: Essays on Philosophical Subjects. Ed. Dugald Stewart. Basel: James Decker, 1799. Seção II, §12, p. 28ss. [N. do T.: SMITH, Adam. History of Astronomy. In: The Glasgow Edition of the Works and Correspondence of Adam Smith - Volume III: Essays on Philosophical Subjects. Ed. Ed. W. P. D. Wightman \& J. C. Bryce. Indianapolis: Liberty Fund, 1982. Seção II, §12, p. 47].
}

de aqui ressaltar com a maior ênfase possível, é o fato de que, seja qual for o grau de rigor das leis próprias dos fenômenos sociais, e independentemente dos resultados a que nos conduzam as investigações acerca da natureza peculiar e das diversas espécies dessas leis, isso, de modo nenhum, afeta o caráter da economia como ciência teórica. Os tipos e as relações típicas da economia podem ser mais ou menos rigorosos, e isso se dá geralmente, não importando a natureza deles; mas, em todo o caso, a essência da economia teórica não pode senão consistir na demonstração desses tipos e dessas relações, ou, em outras palavras, na demonstração da natureza geral e da conexão geral das leis dos fenômenos econômicos, e nunca na exposição do caráter e das relações de fenômenos econômicos singulares, isto é, nas descrições históricas ou em certas regras práticas para a atividade econômica do povo. Não se deve jamais confundir a teoria da economia com as ciências econômicas históricas ou práticas. Apenas aqueles que ignoram absolutamente a natureza e as funções da teoria econômica podem considerá-la uma ciência histórica, pelo fato de que os conceitos gerais (teóricos) que ela adota são, na realidade, ou parecem ser, menos rigorosos do que os das ciências naturais; ou quiçá, como veremos, pelo fato de o desenvolvimento dos fenômenos econômicos não estar isento da influência sobre o modo e a maneira pelos quais a economia cumpre suas funções teóricas. E somente quem não é capaz de distinguir a natureza das ciências teóricas daquela das ciências práticas pode conceber a economia como uma ciência prática - talvez porque, como sucede com outras teorias, ela constitua a base das ciências práticas.

Igualmente errônea é a opinião, bastante comum, de que a economia teórica, pelas razões apontadas, carece de valor como ciência teórica. Ainda que se admitisse a priori, sem maiores investigações, que o conhecimento teórico, no campo dos fenômenos econômicos, carece de um rigor sem igual, e que, em particular, o desenvolvimento de tais fenômenos exclui a possibilidade de leis naturais 
- ainda assim, dizemos, não seria legítimo tirar tal conclusão. Também são poucas as ciências naturais que contêm somente leis naturais totalmente rigorosas; todavia, não duvidamos do valor das que só apresentam leis empíricas. Nenhum cientista da natureza, por exemplo, pensaria em negar o caráter de ciências teóricas para uma série de ciências que descrevem as leis da vida orgânica, pelo simples fato de serem leis empíricas. Cometeríamos a mesma insensatez se, em nosso campo, desdenhássemos da grande ajuda que as ciências, mesmo as pouco rigorosas, nos prestam para a compreensão, a previsão e o controle dos fatos, e se nos limitássemos por isso - por não sermos capazes de formular uma teoria rigorosa dos fenômenos econômicos - à investigação histórica ou estatística, ou mesmo às ciências econômicas práticas. Fazê-lo criaria uma lacuna no sistema das ciências econômicas, lacuna igual à que haveria se se ignorasse a existência das ciências históricas e práticas da economia.

Naturalmente, não carece de importância, seja para a compreensão, seja para a previsão e o controle dos fenômenos, o fato de as leis de sua coexistência e sucessão serem mais ou menos rigorosas. Quanto mais rigorosas essas leis, maior o grau de certeza com que, baseando-se nelas, se pode superar a experiência imediata e chegar a uma conclusão acerca da ocorrência de fenômenos futuros ou da coexistência de fenômenos simultâneos não observados diretamente. Sem dúvida, o fato de as leis da sucessão e da coexistência dos fenômenos não serem rigorosas reduz o grau de certeza das conclusões baseadas nelas, e, portanto, a certeza da previsão e do controle dos fenômenos. Trata-se, no entanto, de uma diferença de grau, não de princípio. Também as ciências teóricas que apresentam somente leis empíricas têm, para a vida humana, grande importância prática, ainda que a certeza absoluta seja substituída por uma maior ou menor probabilidade. Ao contrário, os conhecimentos históricos e a compreensão histórica dos fenômenos não nos oferecem, por si mesmos, tal previsão etc., e, por conseguinte, não podem substituir o conhecimento teórico. $\mathrm{O}$ conhecimento histórico não pode ser senão o material sobre o qual podemos estabelecer as leis dos fenômenos (por exemplo, as leis do desenvolvimento econômico). Mesmo o político prático deve, primeiro, obter conhecimentos gerais (regras) a partir da história, antes de poder tirar suas conclusões sobre a configuração dos acontecimentos futuros.

$\mathrm{O}$ fato de algumas escolas negarem a possibilidade de chegarmos a resultados absolutamente rigorosos, por meio da investigação dos fenômenos econômicos; de, neste campo, surgirem dificuldades desconhecidas em outros ramos das ciências naturais; e de, finalmente, as tarefas da economia teórica não serem da mesma natureza que as das ciências naturais teóricas - todas estas circunstâncias podem certamente conferir à nossa investigação teórica um caráter peculiar e justificar alguns traços próprios, mas jamais podem substituir a investigação teórica pela orientação histórica ou prática. A economia teórica não pode nunca ser vista como uma ciência histórica, nem, como muitos gostariam, como uma ciência prática.

No campo da investigação econômica, devemos evitar um erro duplo. Constituiria um grave engano não reconhecer a peculiaridade deste grupo de fenômenos que chamamos econômicos, e, por conseguinte, não reconhecer a singularidade da tarefa que a investigação teórica nos propõe, no campo econômico. Seria, todavia, um erro ainda mais grave se, por levar em conta a dita peculiaridade, renunciássemos, explícita ou implicitamente, à investigação teórica, ou se, por conceber esta teoria a partir de um ponto de vista especial (histórico, por exemplo), perdêssemos de vista a própria teoria. cos 